\title{
Modelling Value at Risk: Evidence from the Saudi Stock Market
}

\author{
Khalafalla Ahmed Mohamed Arabi \\ Professor of Econometrics and Social Studies \\ College of Business, King Khalid University \\ Hemeda Mohamed Abdelmageed \\ Assistant Professor of Accounting, \\ Faculty of Commerce, Al-Azhar University \\ College of Business, King Khalid University
}

\begin{abstract}
This paper aims to estimate Value at Risk (VaR) of Tadawul All Shares Index of Saudi Stock Market (TASI) over the period January 2004 - December 2017. It applies the following methods, empirical quartile, historical simulation (HS), and percentile, parametric via delta normal, GARCH, IGARCH, Monte Carlo simulation and bootstrapping simulation. It uses $5 \%$ and $1 \%$ critical value under Normal distribution. Back- testing based on likelihood ratio LR accepted empirical quartile at both five and one percent, while accepting delta normal, historical simulation, percentile, IGARCH, and Monte Carlo at one percent. The worst loss obtained is approximately $4 \%$.
\end{abstract}

Key Words: Backtest, Normal distribution, TASI, Value at Risk, worst loss

\section{INTRODUCTION}

There is unanimous agreement about the concept of Value-at-Risk (VaR). All definitions comprise four elements, that is single measure of certain amount of portfolio loss over specified period with a probability $(1-\alpha)$ due to market movements (Linsmeier and Pearson 1996, Manfredo and Leuthold 1998, Tsay 2002, Fernandez 2003, Lamantia, Ortobelli, and Rachev 2006, Čorkalo 2011, Bucevska 20 13, Adabi, Mehrara and Mohammadi 2015, Bingqiu (2016) and Glyon 2017). No doubt, that VaR took great importance since the recommendation of Basel Committee in 1996 (Aloui and Ben Hamida 2015). VaR is the dollar or percentage loss in a portfolio (asset) value that will be equal to or exceeded only $\mathrm{X}$ percent of time.

There was high expectations laid on attracting foreign portfolio investment because of opening the Saudi stock market to foreign portfolio investment since June 2015. Foreign participation would open up opportunities associated with access to a huge untapped market. Saudi stock exchange has met conditions related to "size and accessibility" criterion. Two major risks are probably face KSA that is an increase in short-term volatility in the financial system and its monetary policy being dependent on that of the US (Aljazira Capital 2015). Altogether, these entail estimating as accurate as possible market risk quantification. The Tadawul All Share Index (TASI) is a major stock market index, which tracks the performance of all companies listed on the Saudi Stock Exchange. The year 1985 witnessed the introduction of index has a base value of 1000 and its recognition on June 30, 2008 (Yahoo Finance). However, factors including a strong economy support Tadawul (Aljazira capital 2015).

The motivation behind this paper is the scarcity of empirical research concerning VaR for Saudi Stock Exchange. To my knowledge, only one paper has dealt with estimating Value at Risk for Saudi and Gulf Cooperation Council stock markets (Aloui, and Ben Hemida 2015). The difference between Aloui \& Hemida and me is that they used only non-linear GARCH class 
models to estimate long-memory, asymmetry, and fat tail while I will use nonparametric and parametric tools backed by backtesting to estimate VaR and choose the best tool. The organization of this paper is as follows: literature review, theoretical background, methodology, empirical results, discussion, and conclusion.

\section{LITERATURE REVIEW}

There is a considerable number of empirical papers dealing with measuring and forecasting the value at risk. Below a sample of scholar endeavors to estimate and forecast value at risk for financial and non-financial variables. Holton (2017) explained systematically how to calculate value at risk. Cheung and Powell (2012) and Čorkalo, Šime (2011) demonstrated the usefulness of Excel in calculating value at risk.

GARCH models were suitable methods for calculating value at risk for various stock market as Chinese stock market (Chen, Xibei 2017 Montenegrin emerging market, (Smolović et al 2017), Gulf Cooperative Council stock markets (Aloui, and Ben Hemida 2015). (Bucevska 2013, Yoon, Woo and Kang 2011, and Fernandez 2003) did the same for Shenzhen Component index and Shanghai Composite stock index, Shanghai stock market and Macedonian stock exchange index-MBI 10 and Standard and Poor 500 respectively.

While other scholars using parametric, nonparametric and semi-parametric approaches to estimate VaR for total index of Tehran Stock Exchange (Adabil, Mohsen and Mohammadi 2015), the Croatian capital market (Bogdan, Baresa, and Ivanovic 2015); Shanghai stock market (Chena and Chen 2013). In addition, Rogachev (2002) clarified how banks explain the Value-at-Risk, Goorbergh and Vlaar (1999) applied VaR to the Dutch stock market index AEX and to the Dow Jones Industrial Average.

However, Chang et al (2017) proposed the percentile of cluster method to replace the percentile of statistics in estimating VAR. Zhang, Bingqiu (2016) used Genetic algorithm that is global optimization algorithm, for Shanghai and Shenzhen indices Samanta (2015) examined the performance of the indirect transformation-based approach for the measurement of value at risk (VaR) for selected exchange rates. Manfredo and Leuthold (2016) calculated VaR for agricultural risk management, and Norling and Selling (2012) did the same for the index of Standard \& Poor's 500. Hsieha and Choub presented a hybrid method of estimating VaR, combining Neural Network and autoregressive moving average ARMA.

Alfi and Mishra (2014) employed GARCH-M to assess risk aversion behavior for Saudi financial market. The imperfection and incomplete information of the Saudi stock market is an obstacle to exact volatility prediction.

\section{Parametric Method}

\section{METHODOLOGY}

The first step is to obtain the mean and standard deviation of the normal distribution from historical data, and then we enter [ $\alpha \%$; mean; standard deviation] in Excel function NORMINV. Then multiply by (1-absolute $\alpha \% \mathrm{VaR})$. We use the function NORMDIS (returns, mean, standard deviation, FALSE) to plot the probability density function of the normal distribution (Cheung and Powell 2012). We employ the built-in function NORMINV to calculate the bottom $5 \%$ and $1 \%$ to give value at risk percentages. 


\section{Historical Simulation}

The historical simulation approach requires few assumptions about the statistical distribution of the underlying market factors taking the current portfolio, subject it to the actual change (Linsmeir and Pearsom 1996). It does not constrained by requiring assuming normality. All we need to do is to sort data from worst to best so here we are looking at the tail to answer the question what is the $\alpha \%$ VaR in other words with $(1-\alpha) \%$ confidence level we don't expect the loss to be worse. Then we are answering it by just looking at our historical sample so by means of the percentile function to identify five percent tail of the overall count, the VaR is right outside the five percent tail (Ba ach). Tsay (2001) sets $\Delta V(l)=r_{t}$ be the change in value of the assets in the financial position from time $t$ to $t+l$, designates the cumulative distribution function (CDF) of $\Delta V(l)$ by $F_{l}(x)$.Then states the VaR of a long position over the time horizon $l$ with probability $p$ as:

$$
\begin{gathered}
p=\operatorname{Pr}[\Delta V(l) \leq \operatorname{VaR}]=F_{l}(x) \\
p=\operatorname{Pr}[\Delta V(l) \geq \operatorname{VaR}]=1-\operatorname{Pr}[\Delta V(l) \leq \operatorname{VaR}]=1-F_{l}(x)
\end{gathered}
$$

The VaR in the (1- $\alpha$ ) confidence level is the sample mean minus the percentile of the standard normal distribution multiplied by the portfolio standard deviation (Chen, Chen 2013) That is

$$
\operatorname{Var}=\bar{R}_{p}-Z(\alpha) \times \hat{\sigma}_{p}
$$

\section{Risk Metrics}

In the context of risk measurement, a Risk Metrics is the concept enumerated by a risk measure. When choosing a Risk Metrics, an agent is picking an aspect of perceived risk to investigate, such as volatility or probability of default.

$$
\begin{gathered}
\operatorname{VaR}=\text { Amount of Position }-1.65 \sigma_{t+1} ; \operatorname{VaR}(k)=\sqrt{k} V a R \\
\mu_{t}=0 ; \sigma_{t}^{2}=\alpha \sigma_{t-1}^{2}+(1-\alpha) r_{t}^{2}=\operatorname{IGARCH}(1,1) \text { process without drift }
\end{gathered}
$$

Data: To calculate VaR at 99.9 confidence level, we need not less than1000 observations. Extracting VaR from historical data requires choosing the desired confidence level and picking out the nth observation in the historical data that corresponds to that confidence level. Thus, $\mathrm{VaR}$ is the nth percentile of the values in the chosen data set (Tsay 2002).

\section{Conditional Value at Risk (CVaR)}

$\mathrm{CVaR}$ is generally a better approximation of potential losses for several different scenarios where the highest loss are on the right. We define a probability level (1- $\alpha) \%$ and consider the scenarios whose losses exceed this level. The (1- $\alpha) \%$ defined as the average of losses in these scenarios. It is an average of expected losses of the lowest cases than a wide range of potential losses (Čorkalo 2011). To find exactly how much we will lose in average in our worst-case scenarios we have to look at CVaR values. CVaR $(\alpha \%)$ tells us that in worst ten percent of our returns the average gain will be $0 . x x x$ percent. CVaR $(C L)=1 /$ VaR reference*sum from the first sorted return through VaR cell reference. Count $=$ count built in function, $\mathrm{VaR}$ (CL) reference $=$ (1- confidence level (CL)*count (Uryasev and Stan (2011); Čorkalo 2011, Diedwaedo)

\section{Quantile and Order Statistics}

Assuming that the distribution of return in the prediction period is the same as that in the sample period, one can use the empirical quantile of the return $r$ to calculate VaR (Tsay 2002). Arrange returns in increasing order. Assume that the returns are independent and identically distributed random variables that have a continuous distribution with probability density function (pdf) $f(x)$ and $\operatorname{CDF} F(x)$.

$$
\hat{x}_{p}=\frac{p_{2}-p}{p_{2}-p_{1}} r_{\left(\iota_{2}\right)}+\frac{p-p_{1}}{p_{2}-p_{1}} r_{\left(\iota_{1}\right)} ; \iota_{1}<n p<\iota_{2} ; p_{i}=\frac{\iota_{i}}{n}
$$




\section{Classical value at risk versus GARCH-based models}

Volatility clustering occurs when a period of large returns is followed by a period of small returns (Nelson, 1991). The second property (fat tail) indicates that large positive or large negative observations in financial data occur more frequently as compared to the standard normal distribution. Nonlinear dependence explains the relationship between multivariate financial data. Nonlinear dependence between different assets have co-movement in the same direction relevant to some market conditions (Danielsson, 2011).

\section{Backtesting}

Backtesting refers to testing a predictive model using existing historic data, i.e. a kind of cross validation applied to time series data in trading strategy, investment strategy or risk modeling. It seeks to estimate the performance of a strategy or model if had been employed during the past period then requires simulating past conditions with sufficient details. One limitation of backtesting the need for detailed historical data, a second limitation its mobility to model strategies that would affect historic prices, finally backtesting like other modeling is limited by potential over-fitting i.e. it is often possible to find strategy that would not work well in the future. Despite these limitations, backtesting proved to be a useful tool. Backtesting refers to testing predictive model using existing historic data. It a kind of cross validation (Hurlin and Tokpavi 2014)

\section{Likelihood Ratio}

$$
\begin{gathered}
-2 \log \left((1-p)^{T-N} p^{N}\right)+2 \log \left(\left(1-\frac{N}{T}\right)^{T-N}\left(\frac{N}{T}\right)^{N}\right) ; N / T=\text { expception } \\
L R=+2 \log \left(\left(1-\frac{N}{T}\right)^{T-N}\left(\frac{N}{T}\right)^{N}\right)-2 \log \left((1-p)^{T-N} p^{N}\right) \cong \chi_{1}^{2}
\end{gathered}
$$

We reject the null hypothesis if the outcome is greater than $\chi^{1}(1)$ https://www0.gsb.columbia.edu/faculty/pglasserman/Other/masteringrisk.pdf

\section{Monte Carlo Simulation (MCS)}

Monte Carlo simulation involves conducting repeated trials of the values of the uncertain input(s) based on some known probability distribution(s) and some known process to produce a probability distribution for the output. That is, each uncertain input or parameter in the problem of interest is assumed to be a random variable with a known probability distribution (Čorkalo 2011, Cheung \& Powell 2012). (Chen, Chen 2013) gives the Brownian motion:

$$
S_{t+\Delta t}=S_{t} e^{\left(k \Delta t+\sigma \varepsilon_{t} \sqrt{\Delta t}\right)} ; k=\mu-\left(\sigma^{2} / 2\right)=d r i f t
$$

Where $S_{t}$ is the share price at time $t, e$ is the natural log, $\Delta t$ is the time increment (expressed as a portion of a year in terms of trading days) and $\varepsilon_{t}$ is the randomness at time $\Delta t$ introduced to randomize the change in share price. After some rearrangement the above equation becomes

$$
R_{t+\Delta t}=\ln \left(\frac{S_{t+\Delta t}}{S_{t}}\right)=k \Delta t+\sigma \varepsilon_{i} \sqrt{\Delta t}
$$

Monte Carlo simulation multiplies the last entry by the exponential of the sum of drift and the product of the standard deviation by inverse of the normal distribution.

\section{Bootstrapping Simulation}

The key difference between Monte Carlo simulation and bootstrap is that Monte Carlo uses algorithm to generate portfolio path forward in time whereas bootstrap uses the historical 
return instead of the algorithm. The benefit of the bootstrapping is that it implicitly takes the volatilities and correlations present in the historical data (Dutta and Bhattacharya 2006). The standard steps are first we index the historical returns (daily returns) by means of natural logarithm. The second step is the essence of bootstrapping we randomly select cross-sectional vector that means we go back and select randomly a day from a historical window use that days returns. We use the built-in Excel function [INT(RAND()*last date)+1] to generate random uniform variable that is going to be between $0 \& 1$. Third we random selection to simulate forward that give us the price of portfolio at some point in the future. The fourth step we are going to repeat that as many time as we want which gives us $n$ number of hypothetical portfolio in the future. The final step we sort that list from top to bottom best to worst and look up down the list to find the value at risk. Bootstrapping does not need to specify distributional assumption, not bound to the problem of the normal distribution, the second thing it automatically pick up correlation if it exist between stocks. Bootstrapping is an improvement of basic historical simulation uses random sampling with replacement. Ten day VaR is very common in terms of market risk and stock prices(DuttaA, and Bhattacharya (2006)).

\section{EMPIRICAL RESULTS}

\section{Data}

We downloaded daily data of close prices of TASI from meta-stock covering the period January 2004 to December 2017 containing 3270 observations. We convert the data into log returns (r). There are two advantages of log returns. The main reason why we use log returns because they are time additive (time consistent). The second desirable property is that if these log returns are normally distributed which is a common assumption under short periods then adding these variables produces end log return that is also normally distributed. One disadvantage of log return are not a linear function of the component or asset weights.

\section{Descriptive Statistics}

\begin{tabular}{|l|r|r|r|r|r|r|r|}
\hline Mean & \multicolumn{1}{|c|}{ Median } & Maximum & Minimum & \multicolumn{1}{c|}{ sigma } & Skewness & \multicolumn{1}{c|}{ Kurtosis } & JB \\
\hline-0.00033 & 0 & 0.09531 & -0.10536 & 0.0236 & -0.34753 & 8.53677 & 0 \\
\hline
\end{tabular}

The mean returns is close to zero as well as the median indicates that. There is a wide range of returns, skewed to the left as revealed by the negative sign which is an alarming a matter, while the positive sign of kurtosis suggests leptokurtic distribution means fat tail i.e. higher probability of observations in the tail, too many points cluster close the mean and too many points cluster away from the mean. According to this leptokurtic distribution, we have to be very careful about the negative region. 


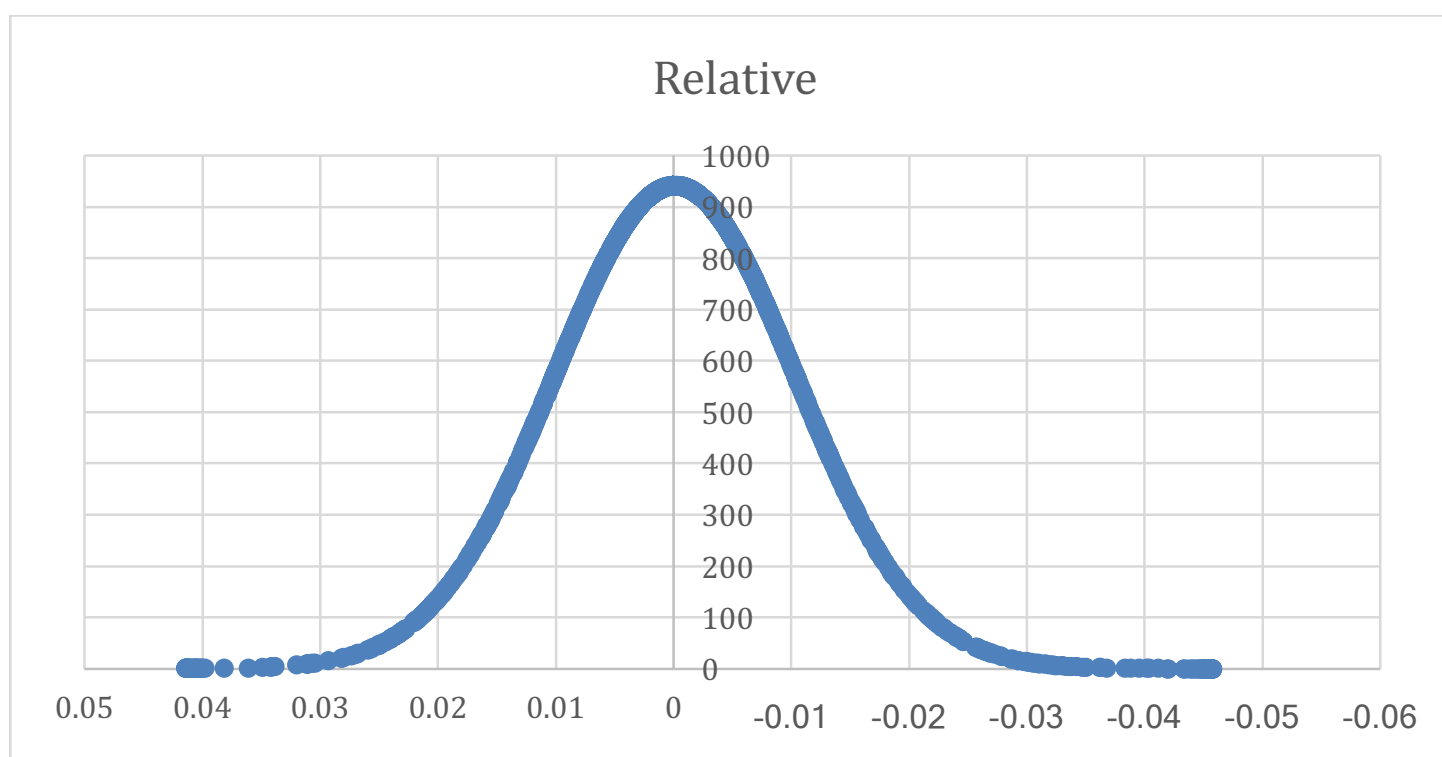

\section{Unit Root Test}

Augmented Dickey Fuller rejects the Null Hypothesis that $r$ has a unit root since all absolute values of t-Statistic at the three critical values $(-3.43216,-2.86223,-2.56718)$ are less than the calculated ADF t-statistic -51.6312 that indicates stationary return data.

\section{GARCH Results}

\begin{tabular}{|l|c|c|c|c|}
\hline Coefficients & GARCH & Coefficients & IGARCH(1,1) & IGARCH(2,1) \\
\hline R & $0.000578^{* *}$ & Constant & $0.000542^{* * *}$ & $0.000363^{* *}$ \\
\hline Constant & $0.0000123^{* * *}$ & & & $0.192986^{* * *}$ \\
\hline$\alpha$ & $0.134302^{* * *}$ & $\alpha$ & $0.047484^{* * *}$ & $-0.160105^{* * *}$ \\
\hline B & $0.84635^{* * *}$ & $1-\alpha$ & $0.952516^{* * *}$ & $0.967118^{* * *}$ \\
\hline DW & 1.78 & DW & 1.79 & 1.79 \\
\hline
\end{tabular}

Results of GARCH $(1,1)$ reveal that the constant term is significant at five percent, whereas news about the volatility from the previous period, and last period forecast variance are significant at one percent. The sum of $(\alpha+\beta=0.134302)$ is less than one indicating convergence to the long-run mean $\frac{\omega}{\alpha+\beta}=\frac{0.0000123}{0.980652}=0.0000125$.

Durbin Watson statistic accepts the null hypothesis on no autocorrelation. GARCH estimation captured ARCH effect. IGARCH(1,1) results show high significance of the estimated news from the previous period, and last period forecast variance. There is no indication of autocorrelation in the series. There still ARCH effect. IGARCH $(2,1)$ removes the ARCH effect.

\begin{tabular}{|l|l|l|l|l|l|l|l|}
\hline VaR & Delta & Quantile & HS & Percentile & \multicolumn{2}{l|}{ GARCH } & \multicolumn{2}{|l|}{ IGARCH(1,)\&(2,1) } \\
\hline $5 \%$ & $-1.7 \%$ & $-1.57 \%$ & $-1.59 \%$ & $-1.57 \%$ & $-3.33 \%$ & $-3.01 \%$ & $-4.3 \%$ \\
\hline $1 \%$ & $-2.4 \%$ & $-3.93 \%$ & $-3.88 \%$ & $-3.90 \%$ & $-4.95 \%$ & $-4.25 \%$ & $-6.08 \%$ \\
\hline LR $_{0.05}$ & 1.197 & -771 & 13.44 & 13.44 & 130.7 & 96.41 & 0.551 \\
\hline LR $_{0.01}$ & 58.68 & 0.0148 & 0.0148 & 0.0148 & NA $^{* *}$ & -235.29 & NA \\
\hline
\end{tabular}

${ }^{*} \mathrm{HS}$ is abbreviation for historical simulation. ${ }^{* *} \mathrm{NA}$ means not available

The value at risk percentages calculated by delta normal valuation method and empirical quantile passed the likelihood rate at $5 \%$ since the calculated LR is less than $\chi_{0.95,1}^{2}$ which is 3.84 . Hence, there is five percent chance to lose $-1.7 \%, 1.57 \%,-4.3 \%$ or more of the index value 
on any given day respectively. The application of the empirical quantile, historical simulation, percentile and IGARCH gave value at risk percentages that passed the LR at $1 \% \chi_{0.99,1}^{2}$ that is 6.63. VaR percentages of the delta normal and IGARCH are two extremes, which are different from the other three methods, lie closely to each other. Thus, the empirical quantile is the only method that passed LR test at both critical values.

\section{Monte Carlo Simulation}

Samples of five period has been forecasted using Monte Carlo simulation, and has been plotted in the following chart.

\section{Monte Carlo Simulation}

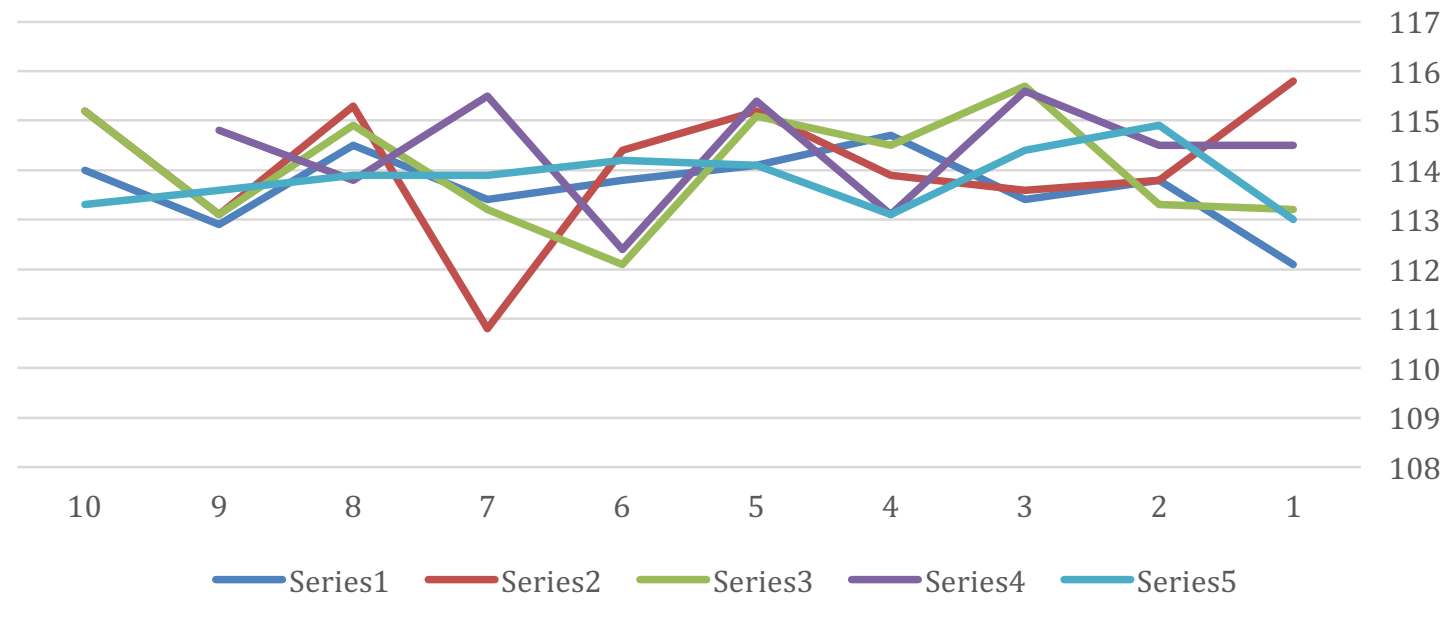

The first, third and fifth series were below 114.1 that is TASI end point indicating negative returns, whereas the second and the fourth series showed gains. Series 2 indicates the worst loss at the seventh period $(-3 \%)$ followed by series $3(-1.9 \%)$ and series $4(-1.4 \%)$ at the sixth period.

\section{Bootstrapping Simulation}

Series 3 showed the worst loss, followed by series 1 and 5 . The first series has the worst loss in the first four of the simulation period. There is apparent difference between simulation results of Monte Carlo and bootstrapping. Negative returns were dominant in bootstrapping

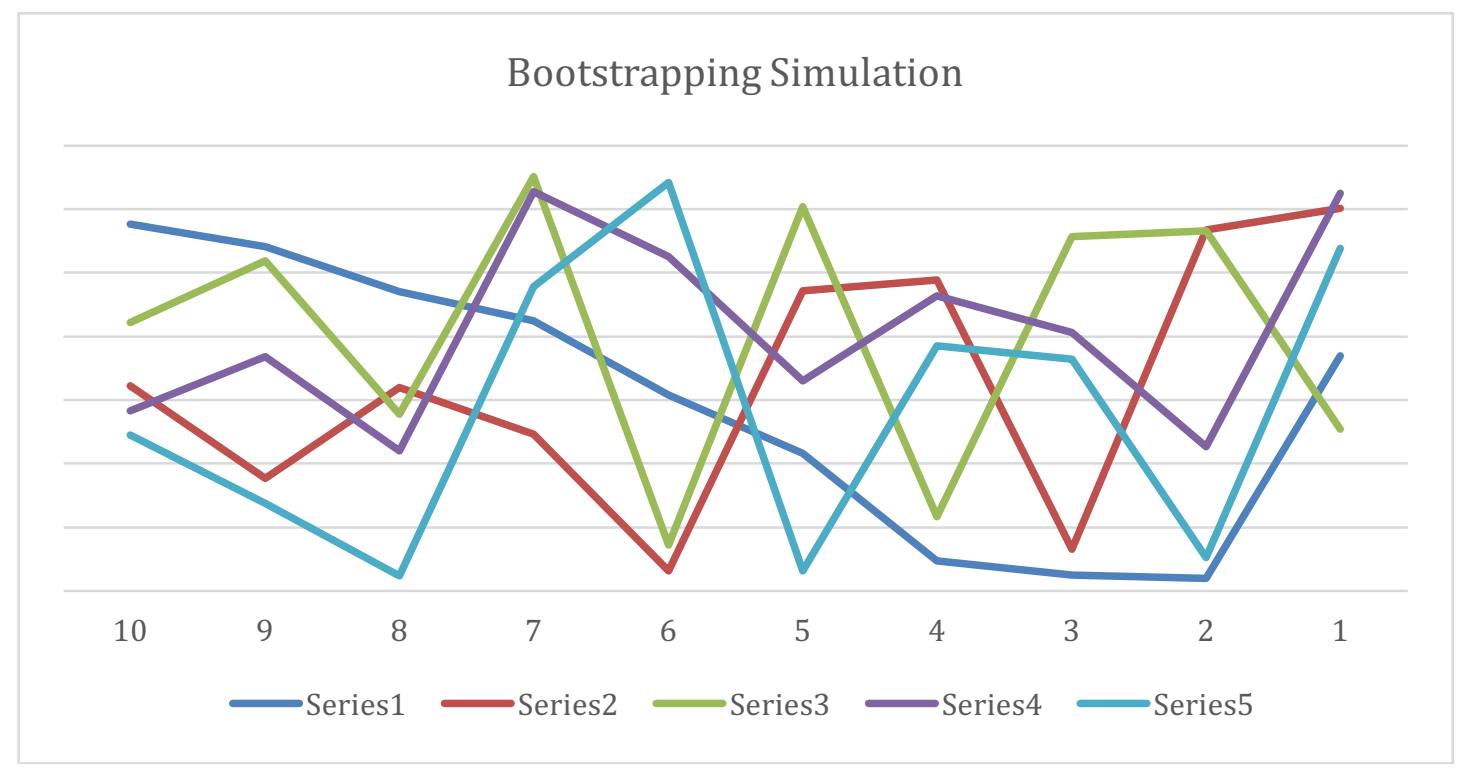




\section{DISCUSSION}

The basic historical simulation is the most popular approach to value at risk employed by companies and banks at least. It assumes mean daily return of zero, often done for a short period. Its advantages stems from its simplicity, flexibility, and free from the complexity of normality assumption. Its major drawback is its need for long time series that requests continuous updating and the jeopardy of picking extreme values. The application of this method to TASI log return introduced two different estimates in magnitude and acceptance by LR backtest. Its VaR 5\% is almost half that of VaR 1\% in addition to its failure to pass the LR test compared to the VaR 1\%. The conditional value at risk is supposed to be an improvement to VaR. It revealed almost two fold VaR percentage compared to basic historical simulation however, it did not pass the LR test. The percentile approach follow suit to historical simulation. The empirical quartile shares the same advantages with the afro said methods; however, its drawbacks are its assumption of unchanging distribution of returns, and its inefficiency if $\mathrm{p}$ is close to zero. Nevertheless, it proved to be the only method that passed the backtest at both levels.

The delta normal approach assumes the prevalence of standard normal distribution. It is an alternative to variance/ covariance approach; nonetheless, it captures only linear risk exposure. Its estimate at five percent level is relatively different from other approaches despites its success in passing the LR test. Its VaR 1\% did not make it. The application of GARCH family to value at risk produced unfavorable results in terms of backtesting passage specifically GARCH $(1,1)$ and IGARCH $(1,1)$. Another drawback of estimated IGARCH $(1,1)$ its failure to remove the ARCH effect, which accomplished by IGARCH $(2,1)$

Bootstrapping simulation is an improvement to basic historical simulation. It showed worst losses compared with Monte Carlo

\section{CONCLUSION}

We converted 3270 data points of TASI into log returns, then various method of VaR calculation. Empirical quantile, basic historical simulation and percentile gave similar results at 99\% confidence level, whereas delta normal and IGARCH are to some extent apart from those results. Backtesting based on likelihood ratio accepted the value at risk percentage by the above-mentioned methods. The empirical quantile is the only method that passed the LR at $5 \%$ and $1 \%$.

\section{References}

Adabi1, Mehrara, Mohsen and Mohammadi, Shapour (2015) Evaluation Approaches of Value at Risk for Tehran Stock Exchange Iran. Econ. Rev. Vol.19, No.1, 2015. P.41-62 https://ier.ut.ac.ir/article_55160_98a7d6824579c8d713bf61ec05b9abac.pdf

Alfi, Ayman F. and Mishra, Tapas K. (2014) Dynamics of Investor Risk Behavior in Emerging Stock Markets: Evidence from Saudi Arabia http://www.sama.gov.sa/en-US/EconomicResearch/WorkingPapers/wp_14_2.pdf

Aloui, Chaker and Ben Hemida, Hala (2015) Estimation and Performance Assessment of Value-at-Risk and Expected Shortfall Based on Long-Memory GARCH-Class Models Czech Journal of Economics and Finance, 65, no. 1- http://journal.fsv.cuni.cz/storage/1315_aloui.pdf

Bogdan, Sinisa, Suzana Baresa, and Zoran Ivanovic. (2015) Estimating Risk on the Capital Market with VaR Method. UTMS Journal of Economics 6 (1): 165-175. 165 Estimating Risk on the Capital Market with the Value at Risk Method www.farmdoc.illinois.edu/nccc134/conf_1998/pdf/confp20-98.pdf

Bucevska, Vesna (2013) an Empirical Evaluation of GARCH Models in Value-at-Risk Estimation: Evidence from the Macedonian Stock Exchange Business Systems Research Vol. 4 No. 1

Chang Hae-Ching, Chen, Cheng-TE, Hsieh, and Chin-Shan (2017) Forecasting of the Value at Risk by using Percentile of Cluster Method 
www.kyu.edu.tw/teacpage/teacpage97/97論文成果彙編/206.pdf

Chena, Qi and Chen Rongda (2013) Method of Value-at-Risk and empirical research for Shanghai stock market www.sciencedirect.com/science/article/pii/.../pdf?md5...pid=1

Cheung, Yun Hsing and Powell Robert J. (2012) anybody can do Value at Risk: A Teaching Study using Parametric Computation and Monte Carlo Simulation Volume 6 | Issue 5 Article $7 \mathrm{http} / / /$ ro.uow.edu.au/aabfj

Chen, Xibei () Empirical Research on Value-at-Risk Methods of Chinese Stock Indexes http://lup.lub.lu.se/luur/download?func=downloadFile\&recordOId=8911356\&fileOId

Čorkalo, Šime (2011) Comparison of Value at Risk Approached on Stock Portfolio Croatian Operational Research Review (CRORR), Vol. 2

https://www.google.com.sa/search?q=Monte+Carlo+Simulation+Value+at+Risk\&safe=strict\&ei=_IMNW4KpI8mH U86mhZAJ\&start $=10 \&$ sa $=$ N\&biw $=1517 \&$ bih $=735$

Diedwardo, Mike, Mad Quant ttps://www.youtube.com/watch?v=2QJykxUNb6I

DuttaA, Debashis and Basabi Bhattacharya (2006) Bootstrapped Historical Simulation Value at Risk Approach to S \& P CNX Nifty http://www.igidr.ac.in/conf/oldmoney/mfc_10/Debashis\%20Dutta_submission_27.pdf

Fernandez Viviana (2003) "Extreme Value Theory and Value at Risk" Revista de Analisis Economico Vol. 18 No. 1 pp 57-85

Goorbergh, Rob van den and Vlaar, Peter (1999) Value-at-Risk Analysis of Stock Returns Historical Simulation, Variance Techniques or Tail Index Estimation https://www.dnb.nl/binaries/sr040_tcm46-146818.pdf

HHarper, David Calculation of Conditional Value at Risk: https://www.youtube.com/watch?v=6Nolb4-iRSI;

Harper, David: Bootstrapping https://www.youtube.com/watch?v=FFSDsTqopZ0

Hurlin, Christophe and Tokpavi, Sessi (2014) Backtesting Value-at-Risk Accuracy: A New Simple Test. International Journal of Forecasting.

https://www.researchgate.net/publication/258049597_Backtesting Value-at-Risk Accuracy A New Simple Test

Fabio Lamantia, Sergio Ortobelli, Svetlozar Rachev () An Empirical Comparison among VaR Models and Time Rules with Elliptical and Stable Distributed Returns

sieha, Chin-Shan and Choub, Jian-Hsin, () Forecasting Value at Risk (VAR) in the Shanghai Stock Market Using the Hybrid Method

https://pdfs.semanticscholar.org/5a5d/c08f1b7e7695138c4d0f5e29e7a4d35a1fb7.pdf

Holton, Glyon (2017) How to Calculate Value-at-Risk - Step by Step https://www.glynholton.com/blog/riskmeasurement/var_measure/

Linsmeier Thomas J. and Pearson Neil D. (1996) "Risk Management: an Introduction to Value at Risk" www.exinfm.com/training/pdfiles/valueatrisk.pdf

ChampaignManfredo, Mark R. and Leuthold Raymond M (2016) Analysis: A Review and the Potential for Agricultural Applications Review of Agricultural Economics--Volume 21, Number 1--Pages 99-111 Value-at-Risk http://citeseerx.ist.psu.edu/viewdoc/download?doi=10.1.1.820.6540\&rep=rep1\&type=pdf

Monteiro, Paulo (2004) Forecasting Hedge Funds Volatility: Value at Risk Approach

Norling, Nicklas and Selling, Daniel (2012) Empirical Evaluation of Value-at-Risk during the Financial Crisis. https://lup.lub.lu.se/student-papers/search/publication/1669008

Provizionatou, Vikentia, Markose, Sheri and Menkens, Olaf (2005) Empirical Scaling Rules for Value-at-Risk (VaR) web.econ.ku.dk/.../provizionatou_empirical\%20scaling\%20rule.pdf

Rob van den Goorbergh and Peter Vlaar (1999) Value-at-Risk Analysis of Stock Returns Historical Simulation, Variance Techniques or Tail Index Estimation

Rogachev, Andrey (2002) Dynamic Value-at-Risk https://www.risknet.de/uploads/tx.../Dynamic-VaR-Rogachev2002.p...

Samanta, G. P (2015) How Good is the Transformation-Based Approach to Estimate Value at Risk Simulation and Empirical Results. National Stock Exchange India WP/16/2015

https://www.nseindia.com/research/content/res_WorkingPaper16.pdf 
Arabi, K. A. M., \& Abdelmageed, H. M. (2018). Modelling Value at Risk: Evidence from the Saudi Stock Market. Archives of Business Research, 6(6), 339-352.

Smolović, Cerović Julija, Milena Lipovina-Božović \& Vujošević, Saša (2017) GARCH models in value at risk estimation: empirical evidence from the Montenegrin stock

Exchange. http://www.tandfonline.com/loi/rero20

Tsay, Ruey S. (2002) Analysis of Financial Time Series John Wiley \& Sons, INC

Uryasev, Stan (2011) VaR vs CVaR in Risk Management and Optimization

http://www.ise.ufl.edu/uryasev/files/2011/11/VaR_vs_CVaR_CARISMA_conference_2010.pdf

Yoon, Seong-Min,, Woo Hyojin and Kang Sang Hoon (2011) VaR Analysis for the Shanghai Stock Market International Conference on Advancements in Information Technology With workshop of ICBMG http://www.ipcsit.com/vol20/42-ICAIT2011-G020.pdf

Zhang, Bingqiu (2016) Stock Market Risk Measurement Method Based on Improved Genetic Algorithm Chemical Engineering Transactions Vol. 51

ANNEX

Annex (1)

Null Hypothesis: R has a unit root

Exogenous: Constant

Lag Length: 0 (Automatic - based on SIC, maxlag=28)

\begin{tabular}{|l|l|r|r|}
\hline \multicolumn{2}{|l|}{} & \multicolumn{1}{l|}{ t-Statistic } & \multicolumn{1}{l|}{ Prob.* } \\
\hline \multicolumn{2}{|l|}{ Augmented Dickey-Fuller test statistic } & -51.6312 & 0.0001 \\
\hline Test critical values: & 1\% level & -3.43216 & \\
\hline & 5\% level & -2.86223 & \\
\hline & $10 \%$ level & -2.56718 & \\
\hline
\end{tabular}

Annex (2)

Dependent Variable: $\mathrm{R}$

Method: ML - ARCH

Date: 05/21/18 Time: 00:41

Sample (adjusted): 23270

Included observations: 3269 after adjustments

Convergence achieved after 24 iterations

Coefficient covariance computed using outer product of gradients

Presample variance: backcast (parameter $=0.7)$

$\mathrm{GARCH}=\mathrm{C}(2)+\mathrm{C}(3) * \operatorname{RESID}(-1)^{\wedge} 2+\mathrm{C}(4) * \operatorname{GARCH}(-1)$

\begin{tabular}{|c|c|c|c|c|}
\hline Variable & Coefficient & Std. Error & z-Statistic & Prob. \\
\hline $\mathrm{C}$ & 0.000578 & 0.000271 & 2.129208 & 0.0332 \\
\hline \multicolumn{5}{|c|}{ Variance Equation } \\
\hline $\mathrm{C}$ & $1.23 \mathrm{E}-05$ & $8.32 \mathrm{E}-07$ & 14.81977 & 0.0000 \\
\hline $\operatorname{RESID}(-1)^{\wedge} 2$ & 0.134302 & 0.00783 & 17.15154 & 0.0000 \\
\hline GARCH(-1) & 0.84635 & 0.007095 & 119.2919 & 0.0000 \\
\hline R-squared & -0.00147 & \multicolumn{2}{|c|}{ Mean dependent var } & -0.00033 \\
\hline Adjusted R-squared & -0.00147 & \multicolumn{2}{|c|}{ S.D. dependent var } & 0.023584 \\
\hline S.E. of regression & 0.023601 & \multicolumn{2}{|c|}{ Akaike info criterion } & -5.13031 \\
\hline Sum squared resid & 1.820374 & \multicolumn{2}{|c|}{ Schwarz criterion } & -5.12286 \\
\hline Log likelihood & 8389.499 & \multicolumn{2}{|c|}{ Hannan-Quinn criter. } & -5.12765 \\
\hline Durbin-Watson stat & 1.784938 & & & \\
\hline
\end{tabular}




\section{Annex (3)}

Dependent Variable: $\mathrm{R}$

Method: ML ARCH - Normal distribution (BFGS / Marquardt steps)

Included observations: 3269 after adjustments

Convergence achieved after 7 iterations

Coefficient covariance computed using outer product of gradients

Presample variance: backcast (parameter $=0.7$ )

GARCH $=\mathrm{C}(2)^{*} \operatorname{RESID}(-1)^{\wedge} 2+(1-\mathrm{C}(2)) * \operatorname{GARCH}(-1)$

\begin{tabular}{|l|r|r|r|r|}
\hline Variable & Coefficient & \multicolumn{1}{l|}{ Std. Error } & z-Statistic & \multicolumn{1}{l|}{ Prob. } \\
\hline C & 0.000542 & 0.000196 & 2.770381 & 0.0056 \\
\hline RESID $(-1)^{\wedge} 2$ & 0.047484 & 0.00107 & 44.36738 & 0.0000 \\
\hline GARCH(-1) & 0.952516 & 0.00107 & 890.006 & 0.0000 \\
\hline R-squared & -0.00135 & Mean dependent var & -0.00033 \\
\hline Adjusted R-squared & -0.00135 & S.D. dependent var & 0.023584 \\
\hline S.E. of regression & 0.0236 & Akaike info criterion & -5.06827 \\
\hline Sum squared resid & 1.820165 & Schwarz criterion & -5.06454 \\
\hline Log likelihood & 8286.088 & Hannan-Quinn criter. & -5.06694 \\
\hline Durbin-Watson stat & 1.785143 & \multicolumn{3}{|}{} \\
\hline
\end{tabular}

Annex (4)

Dependent Variable: R

Method: ML ARCH - Normal distribution (BFGS / Marquardt steps)

Date: 05/24/18 Time: 16:52

Sample (adjusted): 23270

Included observations: 3269 after adjustments

Convergence achieved after 0 iterations

Coefficient covariance computed using outer product of gradients

Presample variance: backcast (parameter $=0.7$ )

$\mathrm{GARCH}=\mathrm{C}(2)^{*} \operatorname{RESID}(-1)^{\wedge} 2+\mathrm{C}(3)^{*} \operatorname{RESID}(-2)^{\wedge} 2+(1-\mathrm{C}(2)-\mathrm{C}(3))^{*} \mathrm{GARCH}(-1)$

\begin{tabular}{|c|c|c|c|c|}
\hline Variable & Coefficient & Std. Error & z-Statistic & Prob. \\
\hline $\mathrm{C}$ & 0.000363 & 0.000173 & 2.100805 & 0.0357 \\
\hline \multicolumn{5}{|c|}{ Variance Equation } \\
\hline $\operatorname{RESID}(-1)^{\wedge} 2$ & 0.192986 & 0.010964 & 17.60205 & 0.00000 \\
\hline $\operatorname{RESID}(-2)^{\wedge} 2$ & -0.16011 & 0.011409 & -14.0328 & 0.00000 \\
\hline $\operatorname{GARCH}(-1)$ & 0.967118 & 0.000943 & 1025.045 & 0.00000 \\
\hline R-squared & -0.00085 & \multicolumn{2}{|c|}{ Mean dependent var } & -0.00033 \\
\hline Adjusted R-squared & -0.00085 & \multicolumn{2}{|c|}{ S.D. dependent var } & 0.023584 \\
\hline S.E. of regression & 0.023594 & \multicolumn{2}{|c|}{ Akaike info criterion } & -5.09272 \\
\hline Sum squared resid & 1.819256 & \multicolumn{2}{|c|}{ Schwarz criterion } & -5.08713 \\
\hline Log likelihood & 8327.057 & \multicolumn{2}{|c|}{ Hannan-Quinn criter. } & -5.09072 \\
\hline Durbin-Watson stat & 1.786035 & & & \\
\hline
\end{tabular}


Annex (5)

\begin{tabular}{|r|c|c|c|c|c|c|c|c|c|}
\hline \multicolumn{1}{|l|}{ Monte Carlo Simulation } & \multicolumn{1}{l|}{ Bootstrapping Simulation } \\
\hline 1 & 2 & 3 & 4 & 5 & 1 & 2 & 3 & 4 & 5 \\
\hline 112.1 & 115.8 & 113.2 & 114.5 & 113.0 & 1849 & 3007 & 1270 & 3126 & 2694 \\
\hline 113.8 & 113.8 & 113.3 & 114.5 & 114.9 & 2124 & 2836 & 2829 & 1133 & 262 \\
\hline 113.4 & 113.6 & 115.7 & 115.6 & 114.4 & 2707 & 325 & 2782 & 2027 & 1819 \\
\hline 114.7 & 113.9 & 114.5 & 113.1 & 113.1 & 95 & 2444 & 583 & 2321 & 1927 \\
\hline 114.1 & 115.2 & 115.1 & 115.4 & 114.1 & 238 & 2354 & 3018 & 1647 & 155 \\
\hline 113.8 & 114.4 & 112.1 & 112.4 & 114.2 & 124 & 158 & 361 & 2625 & 3208 \\
\hline 113.4 & 110.8 & 113.2 & 115.5 & 113.9 & 1083 & 1231 & 3252 & 3134 & 2390 \\
\hline 114.5 & 115.3 & 114.9 & 113.8 & 113.9 & 2349 & 1600 & 1387 & 1099 & 118 \\
\hline 112.9 & 113.1 & 113.1 & 114.8 & 113.6 & 1536 & 882 & 2595 & 1838 & 689 \\
\hline 114 & 115.2 & 115.2 & & 113.3 & 2883 & 1609 & 2107 & 1415 & 1223 \\
\hline
\end{tabular}


Annex (6)

\begin{tabular}{|c|c|c|}
\hline Bin & Frequency & Cumulative \% \\
\hline-0.04576 & 1 & $0.03 \%$ \\
\hline-0.04423 & 20 & $0.64 \%$ \\
\hline-0.0427 & 5 & $0.80 \%$ \\
\hline-0.04117 & 2 & $0.86 \%$ \\
\hline-0.03964 & 3 & $0.95 \%$ \\
\hline-0.03811 & 3 & $1.04 \%$ \\
\hline-0.03658 & 1 & $1.07 \%$ \\
\hline-0.03505 & 2 & $1.13 \%$ \\
\hline-0.03353 & 5 & $1.28 \%$ \\
\hline-0.032 & 6 & $1.47 \%$ \\
\hline-0.03047 & 7 & $1.68 \%$ \\
\hline-0.02894 & 7 & $1.90 \%$ \\
\hline-0.02741 & 4 & $2.02 \%$ \\
\hline-0.02588 & 9 & $2.29 \%$ \\
\hline-0.02435 & 7 & $2.51 \%$ \\
\hline-0.02282 & 9 & $2.78 \%$ \\
\hline-0.02129 & 20 & $3.40 \%$ \\
\hline-0.01977 & 12 & $3.76 \%$ \\
\hline-0.01824 & 11 & $4.10 \%$ \\
\hline-0.01671 & 21 & $4.74 \%$ \\
\hline-0.01518 & 18 & $5.29 \%$ \\
\hline-0.01365 & 24 & $6.03 \%$ \\
\hline-0.01212 & 34 & $7.07 \%$ \\
\hline-0.01059 & 32 & $8.05 \%$ \\
\hline-0.00906 & 58 & $9.82 \%$ \\
\hline-0.00753 & 80 & $12.27 \%$ \\
\hline-0.006 & 117 & $15.85 \%$ \\
\hline-0.00448 & 139 & $20.10 \%$ \\
\hline-0.00295 & 278 & $28.60 \%$ \\
\hline-0.00142 & 387 & $40.44 \%$ \\
\hline 0.000111 & 506 & $55.92 \%$ \\
\hline 0.00164 & 248 & $63.51 \%$ \\
\hline 0.003169 & 294 & $72.50 \%$ \\
\hline 0.004698 & 244 & $79.96 \%$ \\
\hline 0.006227 & 149 & $84.52 \%$ \\
\hline 0.007756 & 93 & $87.37 \%$ \\
\hline
\end{tabular}




\begin{tabular}{|c|c|c|}
\hline 0.009285 & 83 & $89.91 \%$ \\
\hline 0.010814 & 64 & $91.86 \%$ \\
\hline 0.012343 & 39 & $93.06 \%$ \\
\hline 0.013872 & 27 & $93.88 \%$ \\
\hline 0.015401 & 25 & $94.65 \%$ \\
\hline 0.016929 & 29 & $95.53 \%$ \\
\hline 0.018458 & 15 & $95.99 \%$ \\
\hline 0.019987 & 19 & $96.57 \%$ \\
\hline 0.021516 & 25 & $97.34 \%$ \\
\hline 0.023045 & 14 & $97.77 \%$ \\
\hline 0.024574 & 13 & $98.16 \%$ \\
\hline 0.026103 & 12 & $98.53 \%$ \\
\hline 0.027632 & 5 & $98.68 \%$ \\
\hline 0.029161 & 3 & $98.78 \%$ \\
\hline 0.03069 & 3 & $98.87 \%$ \\
\hline 0.032219 & 5 & $99.02 \%$ \\
\hline 0.033748 & 0 & $99.02 \%$ \\
\hline 0.035277 & 4 & $99.14 \%$ \\
\hline 0.036806 & 1 & $99.17 \%$ \\
\hline 0.038335 & 1 & $99.20 \%$ \\
\hline 0.039864 & 1 & $99.24 \%$ \\
\hline More & 25 & $100.00 \%$ \\
\hline Total & 3269 & \\
\hline
\end{tabular}

